\title{
Histopathological and Histochemical Assessment of the Protective Effects of Zinc on Ethanol-Induced Acute Hepatotoxicity in Adult Albino Rats
}

Ahmed TM Elshennawy ${ }^{1,2 *}$, Saadia R Sayed ${ }^{1}$, Entesar A Saber ${ }^{1}$ and Rehab A Rifaai ${ }^{1}$

${ }^{1}$ Department of Histology, Faculty of Medicine, El-Minya University, Egypt

${ }^{2}$ Department of Histology, Faculty of Medicine, Omar Al-Mukhtar University, Libya

\begin{abstract}
Alcoholic hepatotoxicity is a worldwide major cause of death. The objectives of the present study are to evaluate qualitatively as well as to a less extent quantitatively the protective effects of zinc on acute alcoholic hepatotoxicity. Forty five adult male albino rats were equally divided into three groups. Group I, the 'control' one while group II, 'ethanol-treated' was received ethanol with a total accumulative dosage of $15 \mathrm{~g} / \mathrm{kg} / 36$ hours $(10 \mathrm{~g} / \mathrm{kg} /$ day $)$ by three equally divided gavages of $5 \mathrm{~g} / \mathrm{kg} / 12$ hours each, to simulate acute alcohol intoxication or quadruple bingedrinking among humans. Group III, 'zinc/ethanol-treated' was received an intraperitoneal injection of zinc sulfate as $5 \mathrm{mg} / \mathrm{kg} / \mathrm{day}$ for three days before ethanol administration. Qualitative histological and histochemical parameters were undertaken by using hematoxylin and eosin, iron hematoxylin, periodic acid-Schiff and detectors for the activity of succinic dehydrogenase and ATPase. Also some quantitative morphometric parameters were utilized. Ethanol-treated animals showed loss of normal architecture of hepatic lobules, high cellular degeneration and fatty changes, increased apoptosis, marked mitochondrial affection, inflammatory infiltration in portal space and sinusoids, depletion of glycogen content and decrease in the activity of succinic dehydrogenase and ATPase. Zinctreated animals showed ameliorative changes as mild cellular degeneration, proportionally less apoptosis, mild mitochondrial affection, almost no inflammatory infiltration, mild decrease of glycogen content and mild decrease of succinic dehydrogenase activity while ATPase activity was rendered normal. These results conclude that Zinc is an essential hepatoprotective agent against alcoholic hepatotoxicity. Zinc is qualified to be the first essential and the modest trace element in the map of prophylaxis and management of liver diseases. Finally, the classical histological, histochemical and morphometric techniques are fair enough to explore the big picture of these effects.
\end{abstract}

Keywords: Alcohol; Hepatotoxicity; Zinc; Histochemical; Histopathological; Morphometric

\section{Abbreviations}

SDH: Succinic Dehydrogenase; ATPase: Adenosine Triphosphatase; PAS: Periodic Acid-Schiff; Hx\&E: Hematoxylin \& Eosin; Iron-Hx: Iron Hematoxylin

\section{Introduction}

Alcohol abuse and alcoholism are major worldwide health problems since ancient times and first coined medically at 1852 A.C. by Magnus Huss - Swedish professor of medicine - till recorded as the fourth most common cause of death among adults of USA at 1983 [15]. World Health Organization (WHO) reported at least 140 million alcoholics in the world, most of them are not treated and the statistics of National Health Services (NHS) of UK and National Institute of Health (NIH) of USA reported that alcoholics represented about $7.7 \%$ and $15 \%$ of the population of each country respectively [6]. The total alcoholattributable deaths (AAD) from the years 2006 to 2010 was about 88000/ year representing $9.8 \%$ of all deaths in the USA which expensed more than 223.5 billion dollars in the year 2006 alone due to the consequences of excessive alcohol drinking. The most common cause of chronic AAD was alcoholic liver diseases while the most common cause of acute AAD was motor-vehicle traffic crashes among alcoholics [7]. Alcohol affects many systems and organs particularly the liver and gonads by inducing apoptosis, accumulating reactive oxygen species (ROS), DNA oxidation and lipid peroxidation of cell membranes and their proteins [8,9]. Zinc importance comes the second after iron among essential trace metals. It is directly or indirectly involved in the action of $>300$ known enzymes and $>1000$ transcription factors. Its indirect antioxidant effects come through sulfhydryl stabilization and its ability to antagonize the redoxactive transition metals (e.g. iron and copper), and so reducing the formation of $\mathrm{OH}$ from $\mathrm{H}_{2} \mathrm{O}_{2}$ and $\mathrm{O}_{2}^{-}[10,11]$. Zinc is essential for amino acid-nitrogen metabolism, and as a constituent of the antioxidant superoxide dismutase (SOD) being essential for maintaining blood level and absorption of vitamin $\mathrm{E}$ which is considered as the most important natural antioxidant against lipid peroxidation and defending against many degenerative diseases $[12,13]$. Zinc is a cytoprotective element as had been reported six decades ago [14], making the cell more resistant and less vulnerable to apoptotic induction agents. It stabilizes and protects macromolecules (e.g. proteins, DNA and microtubules) from oxidation and proteolysis through inhibiting caspases and interfering the activation of endonucleases [15,16]. Zinc is a second messenger of immune cells and being very useful in reducing infection among the elderly, in the management of Wilson's disease, pediatric acute diarrhea, the common cold and in the prevention of macular degenerationrelated blindness. Zinc is needed at a daily amount between $2 \mathrm{mg}$ for newborn and increasing with growth to be $12 \mathrm{mg}$ (upper limit is $40 \mathrm{mg}$ / day) for adults and being available in rich amount among oysters, red meat, poultry and sea food (e.g. crab and lobsters) and to a moderate

*Corresponding author: Elshennawy TMA, Department of Histology, Faculty of Medicine, Omar Al-Mukhtar University, Tobruk Branch, Libya, Tel:00218-925889859/00201008254493; Fax: 00218694632663; E-mail:ahmadelshennawy@yahoo.com

Received February 23, 2015; Accepted April 06, 2015; Published April 08, 2015.

Citation: Elshennawy ATM, Sayed SR, Saber EA, Rifaai RA (2015) Histopathological and Histochemical Assessment of the Protective Effects of Zinc on Ethanol-Induced Acute Hepatotoxicity in Adult Albino Rats. J Cytol Histol 6: 321. doi:10.4172/2157-7099.1000321

Copyright: (C) 2015 Elshennawy ATM, et al. This is an open-access article distributed under the terms of the Creative Commons Attribution License, which permits unrestricted use, distribution, and reproduction in any medium, provided the original author and source are credited. 
Citation: Elshennawy ATM, Sayed SR, Saber EA, Rifaai RA (2015) Histopathological and Histochemical Assessment of the Protective Effects of Zinc on Ethanol-Induced Acute Hepatotoxicity in Adult Albino Rats. J Cytol Histol 6: 321. doi:10.4172/2157-7099.1000321

amount in beans, nuts, whole grains, dairy products and fortified cereals [17]. The aim of the present study is to evaluate the protective effects of zinc against acute alcoholic hepatotoxicity as regard histopathological and histochemical parameters.

\section{Material and Methods}

\section{Animals and dosage design}

Forty five adult male Sprague-Dawley albino rats aged nine weeks and weighing 200-250 grams were equally divided into three groups i.e. 15/group. Rats were maintained under standard lab conditions with chow and water ad libitum at the animal house, Faculty of Medicine, El-Minya University, with the ethical and technical considerations of animal rights and concerns. Group I was 'control' and received an oral isocaloric maltose solution. Group II was 'ethanol-treated' and received ethanol with a total accumulative dosage of $15 \mathrm{~g} / \mathrm{kg} / 36$ hours $(10 \mathrm{~g} /$ $\mathrm{kg}$ /day) by three equally divided gavages (first dose at $8 \mathrm{am}$ ) of $5 \mathrm{~g} /$ $\mathrm{kg} / 12$ hours each, to produce acute alcohol intoxication. Also, this dose was designed to simulate binge-drinking among humans that was experimented through a mice model of binge drinking by two previous studies $[18,19]$ who utilized 4 doses of $1.5 \mathrm{~g} / \mathrm{kg}$ with a total accumulative dose of $6 \mathrm{~g} / \mathrm{kg}$ body weight with a minor modification by utilizing a higher dose $(10 \mathrm{~g} / \mathrm{kg} /$ day $)$. This rat model was designed to produce acute alcohol intoxication by making its dosage $(5 \mathrm{~g} / \mathrm{kg})$ to exceed 4 times the binge drinking $(1.22 \mathrm{~g} / \mathrm{kg}$ at single occasion) and 19 times the regular daily dose of an alcoholic human $(0.52 \mathrm{~g} / \mathrm{kg} /$ day $)$ that equals 15 or more drinks/week or often 5 or more drinks at a time. One standard drink equals 12 ounce bottle of beer ( $5 \%$ alcohol) or 5 ounce glass of wine ( $12 \%$ alcohol) or 1.5 ounce shot of liquor ( $40 \%$ alcohol) [20]. Group III was 'zinc/ethanol-treated' and received a single daily intraperitoneal injection of zinc sulfate solution (dissolved in sterile distilled $\mathrm{H}_{2} \mathrm{O}$ ) as $5 \mathrm{mg} / \mathrm{kg} /$ day (at $7 \mathrm{am}$ ) for three days, where the last third dose was one hour (at $7 \mathrm{am}$ ) before the first dose of ethanol (at 8 am). Zinc was given intraperitonealy to ensure its full absorption and action while the three days therapy was to ensure harmonization of zinc at a higher level in the body. Zinc dosage $(5 \mathrm{mg} / \mathrm{kg} /$ day $)$ was designed to be higher than the upper daily limit among adult humans which is $0.57-0.67 \mathrm{mg} / \mathrm{kg} /$ day (40 mg/day) [17]. This higher dose of zinc is to overcome the acute ethanol hepatotoxicity, but still far away from zinc acute toxic dose $-\mathrm{LD}_{50}-(\sim 100 \mathrm{mg} / \mathrm{kg})$ and the chronic toxicosis dose $(>2,000 \mathrm{ppm})$ that have been recently reported by Merck Manuals [21]. Four hours following the last treating dose, rats were rapidly sacrificed by ether overdose. Zinc sulfate and all chemicals utilized in the present study were products of Sigma Chemical Company (St. Louis, MO, USA).

\section{Histochemical and histopathological preparations}

Some liver biopsies were rapidly extracted, frozen at $-15^{\circ} \mathrm{C}$ in cryostat and 10 um thick sectioned then incubated in equal volumes of $0.2 \mathrm{M}$ phosphate buffer with $0.2 \mathrm{M}$ sodium succinate to be mixed with equal volume of nitroblue tetrazolium in distilled water solution $(1 \mathrm{mg} / 1 \mathrm{ml})$ for $10-20$ minutes at $37^{\circ} \mathrm{C}$ for histochemical configuration of succinic dehydrogenase (SDH). For ATP ase activity detection, fresh cryostat sections were incubated for 10-60 minutes in lead nitrate substrate medium $(0.125 \%$ disodium ATP, $\mathrm{pH} 7.2$ buffer, $2 \%$ lead nitrate, $2.5 \%$ magnesium nitrate and distilled water). Other liver biopsies were fixed in $10 \%$ buffered formal saline, dehydrated in ascending grades of ethanol, cleared in xylene, infiltrated-impregnated in soft paraffin at $50^{\circ} \mathrm{C}$ and embedded in paraplast paraffin wax. Solid paraffin blocks were cut into 5 um thick sections by rotator microtome and then mounted on glass slides covered by albumin glycerin. Staining by hematoxylin and eosin was utilized to explore histological structure and apoptotic changes among hepatocytes. Iron-hematoxylin stain was utilized to explore mitochondria by adding equal amounts of solution $\mathrm{A}$ (one gram of hematoxylin to $100 \mathrm{ml}$ distilled water) with solution B (4 $\mathrm{ml}$ of $30 \%$ aqueous ferric chloride to $1 \mathrm{ml}$ of concentrated hydrochloric acid then added to $95 \mathrm{ml}$ of distilled water) then stain sections for 5-15 minutes. Periodic acid - Schiff (PAS) to detect glycogen content was used by bringing sections to water then oxidize for 5 minutes in $1 \%$ aqueous periodic acid, washed in tap water and rinsed in distilled water then placed in Schiff's reagent for 10-20 minutes and finally counter stained with hematoxylin $[22,23]$.

Multiple histological and histochemical stains were utilized to ensure reliability of these techniques in explaining the parallel results whether confirmatory or contradictory.

\section{Morphometric and statistical survey}

Morphometric survey was done through counting 10 fields/ rat biopsy to detect the ratio between apoptotic cells to the total cell number among all the three groups. The statistical data was analyzed for the mean, standard deviation (SD), range and variance of multiple group comparisons by using One-Way ANOVA (IBM" SPSS Statistics, Version 22). Significance was set at $P<0.05$ level.

\section{Results}

\begin{tabular}{|l|c|c|c|}
\hline \multicolumn{2}{|c|}{ Group } & $\begin{array}{c}\text { Apoptotic } \\
\text { Cell Ratio }\end{array}$ & P-value \\
\hline \multirow{3}{*}{ I Control } & Range & $2 \%$ & \\
\cline { 2 - 4 } & Variance & 0.267 & \\
\cline { 2 - 4 } & Mean \pm SD & $1.133 \% \pm 0.516$ & \\
\hline \multirow{3}{*}{ II Ethanol } & Range & $4 \%$ & \\
\cline { 2 - 4 } & Variance & 1.552 & $<0.001^{*}$ \\
\hline \multirow{3}{*}{ III Zn/Ethanol } & Mean \pm SD & $8.467 \% \pm 1.246$ & \\
\cline { 2 - 4 } & Range & $1 \%$ & $<0.001^{*}$ \\
\hline
\end{tabular}

$P<0.05$ is significant

$\mathrm{P}<0.001$ is highly significant

*Studied group versus control

-Studied group versus ethanol-treated group

Table 1: Apoptotic cell ratio (Mean \pm SD) among the 3 experimental groups

\section{Control $\square$ Ethanol $\square \mathrm{Zn} /$ Ethanol}

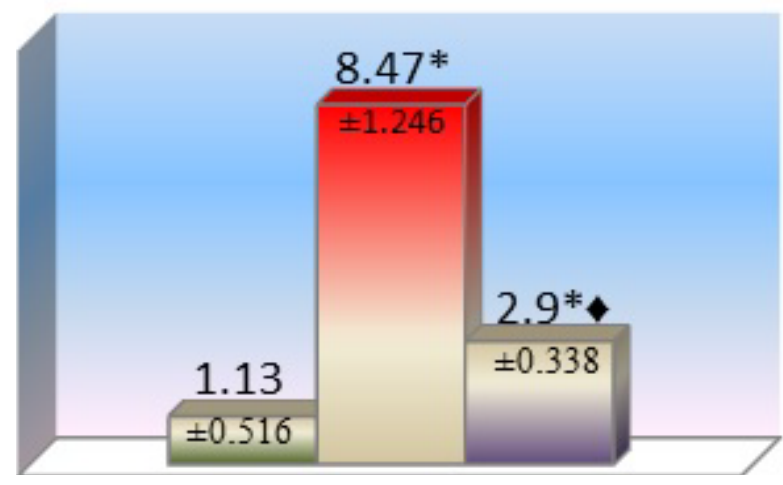

*Studied group versus control

-Studied group versus ethanol-treated group

Figure 1: Percentage ratio (\%) of apoptotic cells (Mean $\pm S D$ ) among the 3 groups 
Citation: Elshennawy ATM, Sayed SR, Saber EA, Rifaai RA (2015) Histopathological and Histochemical Assessment of the Protective Effects of Zinc on Ethanol-Induced Acute Hepatotoxicity in Adult Albino Rats. J Cytol Histol 6: 321. doi:10.4172/2157-7099.1000321

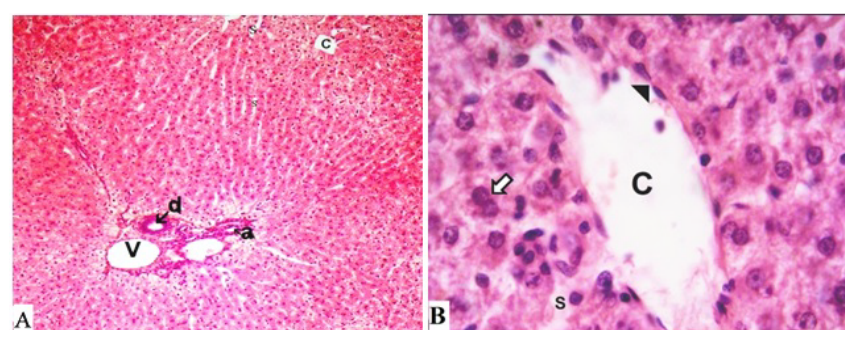

Figure 2: A and B Control group liver sections micrographs. Normal architecture with normal hepatocytes cords around central veins $(C)$ and sinusoids (S). Intact normal endothelium (arrowhead) appeared lining central veins, sinusoids and branches of portal vein $(\mathrm{V})$ and hepatic artery (a), and the bile duct (d) showed intact and regular epithelium. Hepatocytes appeared with eosinophilic cytoplasm, vesicular nuclei and prominent nucleoli while some hepatocytes appeared binucleated (white arrow). (100X for Figure A and 1000X - oil immersion - for Figure B, Hx\& E).

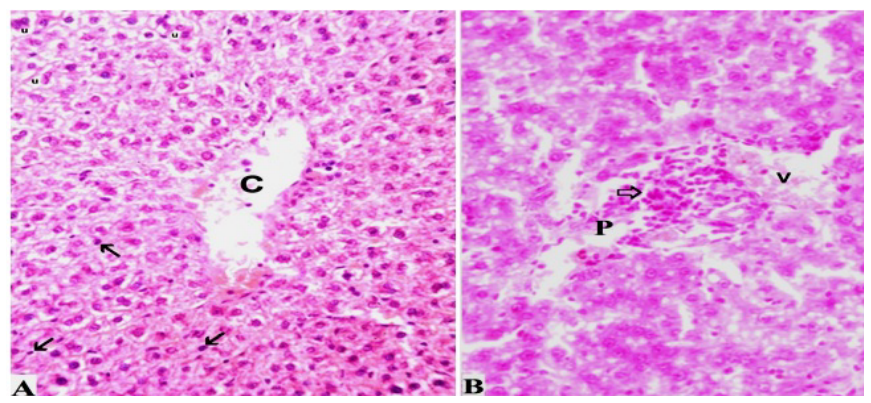

Figure 3: A and B Photomicrographs of ethanol-treated liver sections showed disturbed architecture of hepatocytes plates around central vein (C) and portal tract $(P)$ which showed inflammatory cells infiltration (transparent arrow) encroaching portal vein (v). Degenerating hepatocytes showed cytomegaly, fatty changes and vacuoles (u) while apoptotic cells were numerous and shrunken (dark arrows) with pyknotic nuclei. (400X, Hx\&E).

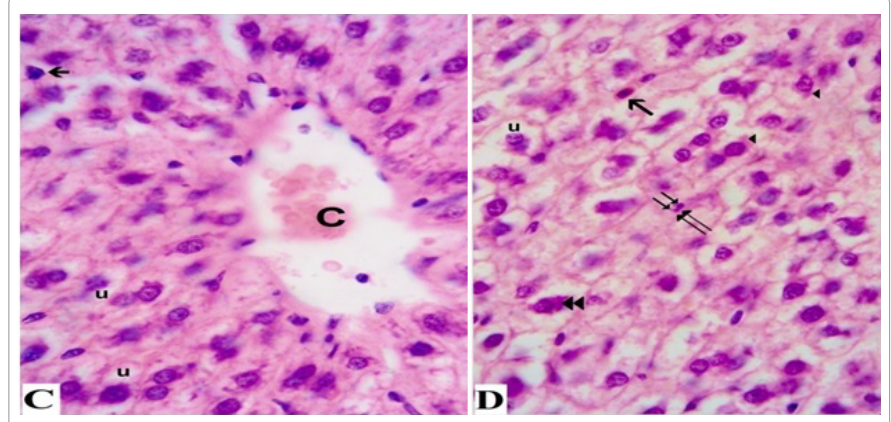

Figure 3: C and D Photomicrographs of ethanol-treated liver sections showed degenerating hepatocytes with fatty changes vacuoles $(u)$ and eosinophilic alcoholic hyaline Mallory bodies (arrowheads) which appeared condensed with basophilic disintegrating cytoplasmic content (double arrowheads) in some other cells. Hepatic blood sinusoids were not apparent between the vacuolated hepatocytes and the disfigured architecture. Apoptotic cells were shrunken and numerous (arrows) with pyknosis and karyorrhexis of nuclei (double arrows). (1000X, oil immersion, Hx\&E).

Morphometric results were represented in Table 1 as the ratio of apoptotic cells among ethanol-treated group was highly significant when compared to that of control group. This ratio showed marked and significant decrease among zinc/ethanol-treated group when compared to ethanol-treated group but still significantly higher than that of the control group at value of $P<0.001$.
In Figure 1, a chart declared the high increase of the apoptotic cell ratio due to ethanol treatment (Group II) and the marked decline of this ratio due to zinc supplementation (Group III) before ethanol administration; however zinc-treated group was still higher than the normal ratio of the control group.

Morphological histology of the control liver tissues using hematoxylin and eosin stain showed normal hepatic stroma and parenchyma. It also showed radial- arranged cords of hepatocytes with eosinophilic cytoplasm, rounded vesicular nuclei and prominent nucleoli while the blood sinusoids, central vein and portal tract contents appeared normal with intact endothelium for blood or lymph vessels and intact epithelium for bile ducts (Figure 2A and 2B) as being studied in different Histology Texts [24,25].

Ethanol-treated animals showed disturbed architecture of the hepatic plates with many enlarged (cytomegaly) vacuolated degenerating cells having indistinct boundaries and pale cytoplasm with fatty changes (steatosis) and collections of eosinophilic alcoholic hyaline Mallory bodies. Blood sinusoids were not apparent between the vacuolated hepatocytes and the disfigured architecture. Apoptotic cell number was increased showing shrinkage, hypereosinophilic cytoplasm and pyknotic (condensed chromatin) or fragmented (karyorrhexis) nuclei. Portal tracts were infiltrated with many inflammatory cells (Figure 3).

Zinc/Ethanol-treated rats showed less affected hepatic tissue architecture and almost no inflammatory cells infiltration. Hepatocytes appeared with distinct boundaries, moderate amount of vacuoles, mild cytomegaly and almost normal cytoplasmic acidophilia. Apoptotic cells were minimally increased while alcoholic Mallory bodies were almost absent among minimal degenerating hepatocytes (Figure 4).

Iron-hematoxylin stain for control liver sections showed mitochondria as dark brownish black granules in fair amounts and regular distributions intracellularly. The centrilobular area that contacts the central vein (Zone 3 of hepatic acinus) [25] showed less affinity than the next area (Zone 2; midway towards portal tract) (Figure 5A). Ethanol-treated rats showed moderate mitochondrial reaction with faint granular staining (Figure 5B). Zinc/Ethanol-treated rats showed good mitochondrial staining as dark brownish black granules with mild affection (Figure 5C).

Histochemical periodic-acid and Schiff reagent (PAS) showed a very strong reaction among control liver sections (Figure 6A) while the ethanol-treated rats showed weak reaction (Figure 6B) with great depletion of glycogen content among this group. Zinc/Ethanol-treated

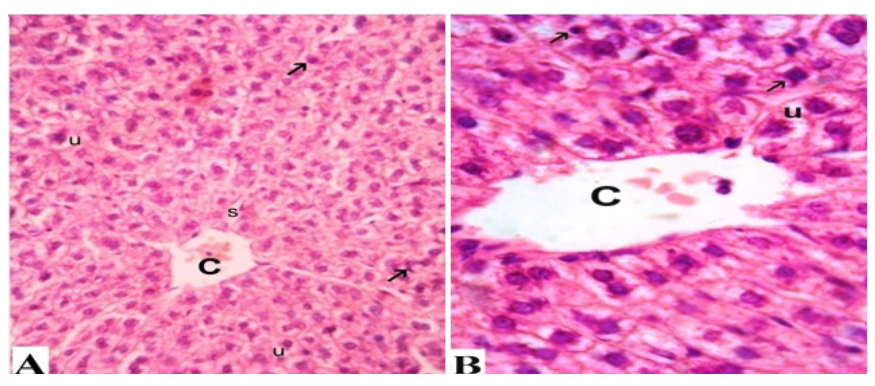

Figure 4: A and B Zinc/Ethanol-treated liver sections micrographs showed normal architecture, no inflammatory cells infiltration and intact endothelium among central veins (C) and sinusoids (S). Hepatocytes with normal eosinophilia, clear cell boundaries, moderate fatty changes or vacuolations (u) and almost no alcoholic Mallory. 
Citation: Elshennawy ATM, Sayed SR, Saber EA, Rifaai RA (2015) Histopathological and Histochemical Assessment of the Protective Effects of Zinc on Ethanol-Induced Acute Hepatotoxicity in Adult Albino Rats. J Cytol Histol 6: 321. doi:10.4172/2157-7099.1000321

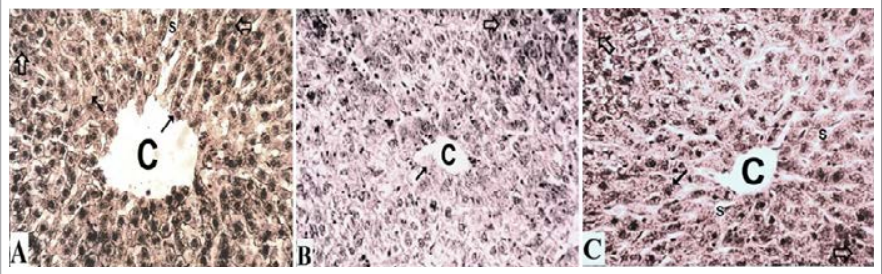

Figure 5: Photomicrographs of Iron-Hx. stained liver sections showed A: control group with normal intracellular mitochondrial content and distribution, B: ethanol-treated rats showed moderate depletion of mitochondrial content, and C: zinc/ethanol-treated rats explored mild mitochondrial affection. Higher mitochondrial affinity was apparent in zone 2 (transparent arrows) than that in the centrilobular zone 3 (dark arrows) around the central vein $(\mathrm{C})$ in the three animal groups. Blood sinusoids $(\mathrm{S})$ were not apparent in ethanol-treated rats. (X400, Iron-Hx).

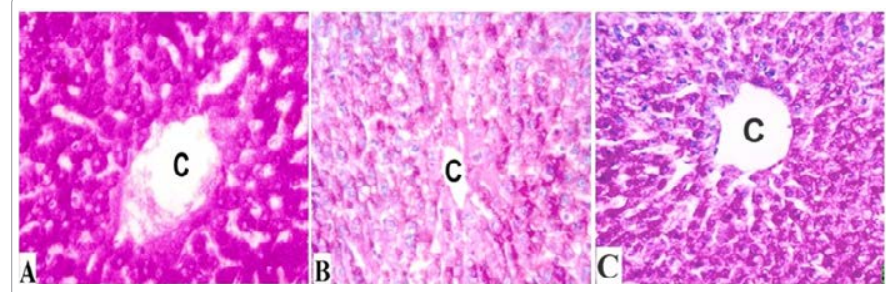

Figure 6: Photomicrographs of PAS-reacted liver sections showed A: control group with very strong normal reaction, B: ethanol-treated rats with weak reaction, and $\mathbf{C}$ : zinc/ethanol-treated rats with moderate-strong reaction indicating the cytoplasmic glycogen content among the three groups. C indicates central vein. (400X, PAS)

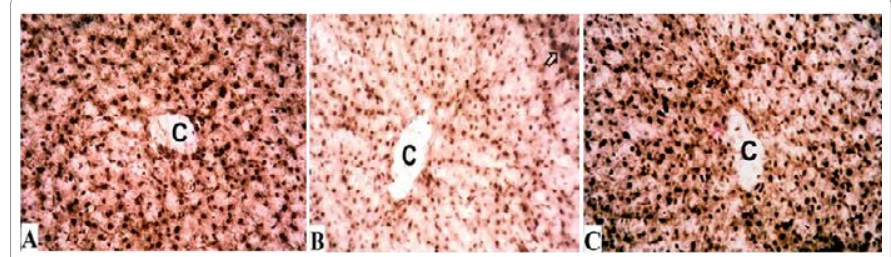

Figure 7: Photomicrographs of ATPase reacted liver sections showed A: control group with strong-positive activity, B: ethanol-treated group with weak positive activity especially the centrilobular area (C) while zone 2 showed mild-moderate activity (arrow), and C: Zinc/Ethanol-treated rats appeared almost normal with strong-positive activity. (400X, ATPase).

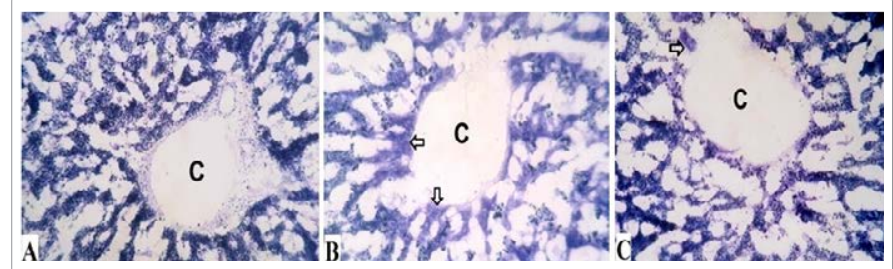

Figure 8: Photomicrographs of SDH reacted liver sections showed $\mathbf{A}$ : control group with strong-positive activity in the form of purple-violet difromazan granules, B: ethanol-treated rats with weak positive activity especially around central veins $(C)$ while zone 2 showed mild activity (granules), and C: Zinc/Ethanol-treated rats with moderate-strong SDH activity while some centrilobular cells appeared negative (arrows) with homogeneously purple cytoplasm that had no SDH granules. (400X, SDH).

animals showed moderate-strong reaction (Figure 6C) that still less than that of the control group.

Histochemical ATPase activity was strong-positive among control group hepatocytes both in the cytoplasm and the nuclei in the form of dark brown fine granules (Figure 7A). Ethanol-treated rats showed weak ATPase activity among the cytoplasm especially in the centrilobular areas around the central veins (Figure 7B). Zinc/Ethanol-treated rats showed strong-positive activity (Figure 7C) which was almost of the same degree of the control rats.

Histochemical succinic dehydrogenase (SDH) activity gave strongpositive reaction with control liver sections in the form of purple-violet difromazan granules especially among mitochondria while the nuclei were negative with no stain (Figure 8A). Ethanol-treated rats showed weak SDH activity especially around the central veins $(\mathrm{C})$ where the cytoplasm was homogeneously purple without difromazan granules (Figure 8B). Zinc/Ethanol-treated animals showed moderate-strong SDH activity with prominent difromazan granules (Figure 8C).

\section{Discussion}

Alcohol abuse and alcoholism are major international issues to evaluate and re-evaluate their massive effects as regard prevention, prophylaxis, palliation, remedy and management at all levels of social, economical, political, environmental and medical sciences ever known $[2,3,7,9]$. The present study passed through many qualitative and some quantitative parameters to assess and re-evaluate many previous studies about the dramatic acute effects of alcohol on the biggest and highest metabolically active gland; the liver, and the fascinating effects of zinc; one of the most essential trace elements of human body even before its confirmed essentiality at $1963[5,9,11,13,26,27]$.

Statistical analysis of the present study showed that acute alcohol administration caused significant wide spread hepatocytic apoptosis which was in agreement with some previous studies [19,28-31]. Some studies postulated that acute ethanol intake induces apoptosis through caspase-3 activation pathway mediated by Fas/Fas L (CD95 L) system signaling [19,32-35] which came in harmony with apoptosis pathways suggested by other previous authors. In addition to increased apoptosis, hematoxylin and eosin staining showed portal tract inflammatory cells infiltration and disturbed architecture of the hepatic plates and many enlarged (cytomegaly) vacuolated degenerating cells with fatty changes (steatosis) and collections of eosinophilic alcoholic hyaline Mallory bodies. This was in agreement with Kawahara et al. [36] who suggested that apoptosis is considered to eliminate hepatocytes containing Mallory bodies while Chomette et al. [37] considered that these changes may initiate autoimmune responses.

Fatty changes (steatosis) and accumulation of lipid among hepatocytes due to ethanol intake was recorded also by previous studies [31,38] and explained by Garcia-Villafranca et al. [39] who postulated that ethanol induces a desensitization of cGMP-mediated regulation of fatty acids metabolism and leads to triacylglycerol accumulation. Alcoholic micro vesicular steatosis and necrosis of hepatocytes were also explained by Lambert et al. [28] who suggested that ethanol increases intestinal permeability to endotoxins which stimulate Kupffer cells to release TNF- $\alpha$ (tumor necrotic factor-alpha) which has direct toxic effects on hepatic parenchyma.

With iron-hematoxylin stain, mitochondria showed moderate depletion of affinity among ethanol-treated liver sections with cytomegalic degenerating cells especially the centrilobular - perivenous - areas. These results were parallel to some previous studies $[6,37,40]$ who recorded mitochondrial swelling (megamitochondria), variant sizes and shapes with reduced or absent cristae. This was explained by some authors [41,42] who attributed these effects to alcoholic oxidative stress and accumulation of reactive oxygen species (ROS) which 
cause oxidative damage to mitochondrial proteins, mitochondrial DNA (mtDNA) and phospholipids of cell membranes. Accumulation of ROS due to alcohol may also explain the lower stain affinity of the perivenous - centrilobular - areas even among the control group with proportional differences with the other two groups when compared with the periportal which has better nourishment and oxygenation and less metabolic waste load.

Histochemical survey of the ethanol-treated liver sections by PAS reaction showed marked depletion of glycogen content which was in accordance with some previous studies $[9,43]$ who postulated that this is mainly due to zinc depletion after ethanol intake. However, glycogen depletion may also be rendered to the aforementioned ethanol-mediated oxidative stress that delays glycogenesis and glycogenolysis as well as mitochondrial function. This was also clear with histoenzymological survey through histochemical ATPase and SDH tests which showed marked decrease of these two enzymes activity among ethanol-treated group especially in the centrilobular - perivenous - areas. The marked decrease of the activity of these two enzymes came in accordance with some previous studies $[28,37,44]$ who suggested an ethanol-mediated failure of metabolic pathways especially ATP production. Furthermore, some previous authors [45] reported that the primary target of ethanolinduced ROS attack is the cellular proteins which may affect metabolic key enzymes. Fucci et al. [46] counted 10 key role enzymes especially those of nitrogen metabolism as glutathione synthetase (GS) which is localized exclusively in the perivenous (centrilobular) areas of hepatic lobules among the intragastric ethanol-fed animal model $[47,48]$.

Perivenous (centrilobular) affection as regard ATPase and SDH was more apparent than that among PAS reaction. This could be explained by the use of the present study an acute short-term model of alcoholism that made a rapid affection of enzymatic activity when compared with glycogen storage and metabolism which require longer time to be apparent among different zones of hepatic lobule or acinus. This explanation was suit with the postulate of Zhou et al. [19] who noticed that chronic alcoholism causes more morphological affection (as apoptosis and glycogen storage) than acute alcoholism could cause. On the other hand, Lambert et al. [28] found that acute alcoholism affects apoptosis primarily in the perivenous -centrilobular- areas which can be considered as regard apoptosis while glycogen storage affection requires chronic ethanol intake to show apparent differences as regard all zones of the hepatic acinus [26].

Zinc pretreated alcoholic rats of the present study showed significant lower number of apoptotic cells which was fit with some previous studies $[28,49,50]$ who explained the cytoprotective effects of zinc as it abrogates or down regulates Fas/FasL-mediated caspase- 8 activation and the subsequent cleavage of pro-caspase- 3 to caspase- 3 , so prevents or diminishes ethanol-induced caspase- 3 activation. In addition, zinc suppresses necrosis through inhibiting lipid peroxidation and the oxidative stress process as being discussed before by some authors [51-56].

However, another study [57] found that zinc accumulation is diminished early in the course of prostate malignancy and it inhibits the growth of several carcinoma cells through induction of cell cycle arrest and apoptosis by modulating the expression of IGF system components and its signaling molecules. This may look contradictory to the present study as regard zinc suppression to the increase of ethanol-induced apoptosis, which could be explained by the distinction of zinc reaction towards growth factors of cancer cell rather than its reaction to the cytotoxic agents as ethanol. This also might be explained according to the ethanol-induced metabolic failure especially to ATP production which directs the switch in pathway to apoptosis or necrosis as reported by a previous study [58]. Furthermore, the results of the present study were parallel to some previous authors who studied apoptosis and the protective effects of zinc against forebrain ischemia [59], sporidesmininduced apoptosis in macrophages and $\mathrm{T}$ lymphoblasts [60], cadmiuminduced hepatotoxicity and nephrotoxicity [61] and even against radiation lethality in mice [62].

Zinc/Ethanol-treated rats of the present study showed minor fatty changes (steatosis), degenerative changes and necrosis of hepatocytes when compared with ethanol-treated hepatocytes. These results were concordant with some authors $[9,28,63]$ who postulated that zinc protects and stabilizes macromolecules (e.g. proteins, microtubules, DNA) and subcellular organelles' membranes from oxidation and proteolysis. So, zinc suppressed ethanol-induced lipid peroxidation and glutathione depletion and reversed the ethanol-induced cGMP desensitization in fatty acid metabolism to prevent triacylglycerol accumulation which was discussed before by some authors $[39,41,54,56]$ who mainly attributed this to accumulation of reactive oxygen species resulted from ethanol-induced oxidative stress. This came in harmony with some previous authors [28,64] who explained the markedly decreased incidence of degenerating-necrotic cells, apoptotic cells and inflammatory cells infiltration among zinc pretreated alcoholic group, by zinc preservation to intestinal barrier against endotoxins and in turn prevents their interaction with Kupffer cells to produce TNF- $\alpha$ which is responsible for stimulation of degeneration-necrosis, apoptosis and inflammation. Furthermore, this could come in agreement with Caballeria et al. [65] who postulated that zinc increases gastric alcohol dehydrogenase activity thereby increases first pass alcohol metabolism and so minimizing the hepatic alcohol load.

Histochemical survey of zinc/ethanol-treated liver sections by PAS reaction in the present study showed fair amount of glycogen content, while the histoenzymological survey of ATPase and SDH tests showed moderate to strong activity of these two enzymes which came in accordance with some previous studies $[9,43,66]$. This was explained by the guarding role of zinc against the ethanol-induced mechanisms discussed by some previous authors $[28,37,44]$ who suggested an ethanol-mediated failure of metabolic pathways especially ATP production. However, glycogen content amelioration might also be attributed to zinc protection against ethanol-mediated oxidative stress which delays glycogenesis and glycogenolysis as well as mitochondrial function detected in the present study by iron-hematoxylin test and recorded before by some previous studies $[9,28,40,42]$.

Hepatic sections architecture was disfigured and blood sinusoids were not apparent among ethanol-treated group which could be explained by cytomegaly, steatosis (fatty changes) and vacuolations of degenerating hepatocytes and increased number of apoptotic cells that might be collectively attributed as an acute ethanol parenchymal injury. Also, this could be explained according to one previous report [67] who claimed that alcohol would induce the release of bacterial endototxin from gut which might cause inflammatory cells infiltration which would compress the sinusoids, while alcohol induced release of endothelins from sinusoidal endothelium would diminish sinusoidal lumen by the vasoconstrictive effect on perisinusoidal stellate cells. Additionally, the stroma was presumably injured as what had been inferred before by Dashti et al. [66] that zinc supplementation to cirrhotic liver leads to decrease in fibrin, reticulin and collagen and concluded that zinc is needed not only to protect against acute ethanol injury but also to treat even late stages of alcoholic liver injury as fibrosis and cirrhosis.

The present study utilized male rats only i.e. of the same gender, to 
Citation: Elshennawy ATM, Sayed SR, Saber EA, Rifaai RA (2015) Histopathological and Histochemical Assessment of the Protective Effects of Zinc on Ethanol-Induced Acute Hepatotoxicity in Adult Albino Rats. J Cytol Histol 6: 321. doi:10.4172/2157-7099.1000321

avoid the sex difference that was established as regard alcohol-related organ injury and studied before by many authors as Sato et al. [68]. The present study utilized zinc pretreatment as an intraperitoneal injection and not oral route, to avoid zinc absorption depletion by ethanol which was recorded before by some previous authors $[17,69]$, in addition to the ethanol-induced increase of intestinal permeability to endotoxins that would interfere with zinc absorption [28]. Ethanol was given as an acute intake by gavage at a dose of $5 \mathrm{~g} / \mathrm{kg} / 12$ hours for 3 doses, which was toxic by exceeding the ethanol intake among human heavy (excessive) drinkers who utilized more than the limit of an alcoholic $(0.52 \mathrm{~g} / \mathrm{kg} /$ day $)$ as had been recently defined by U.S. National Institute of Health (NIH) [20]. The ethanol dose of the present study was $5 \mathrm{~g} /$ $\mathrm{kg} / 12$ hours i.e. equivalent to $10 \mathrm{~g} / \mathrm{kg} /$ day and considered similar to oral median lethal dose $\left[\mathrm{LD}_{50}\right](9.9 \mathrm{~g} / \mathrm{kg})$ of ethanol administration utilized before by a previous study among mice [70] and about $1.1-1.4$ times the oral $\mathrm{LD}_{50}$ among rats $(7-9 \mathrm{~g} / \mathrm{kg})[71,72]$ to produce acute alcohol intoxication. The acute alcohol intoxication model of the present study was parallel to some previous studies among humans [73,74].

In the present study zinc dosage was $5 \mathrm{mg} / \mathrm{kg} /$ day for three days before ethanol administration which was parallel to the effective antilethal dose measured by some previous studies [70,75] which utilized 15 $\mathrm{mg} / \mathrm{kg}$ once intraperitonealy 60 minutes before ethanol administration and they considered this procedure would offer maximum protection against the lethal effect of acute ethanol intake. On the other hand, our experimental design was contradictory to one recent study [76] who administered the antioxidant agent (Propolis) orally one hour after the administration of the toxic agent (Fenvalerate; A Pyrethroid Insecticide) which resulted in ameliorative effects in the aforementioned study rather than the protective effects seen in the present study and other similar studies $[17,69,70,75]$ where the antioxidant (Zinc) was administered through intraperitoneal route before the administration of the toxic agent (Ethanol). Furthermore, the present study avoided zinc overdosage which was reported by some previous studies as $[77,78]$ where zinc overdose was $5-10 \mathrm{ppm}$ water for experimental fish and $19 \mathrm{mg} / \mathrm{kg}$ body weight for experimental rats and caused severe degeneration, hemorrhage and necrosis in seminiferous tubules and fibrosis in the interstitial tissue. Lastly, the utilized dose of zinc in the present study $(5 \mathrm{mg} / \mathrm{kg} / \mathrm{day})$ was very far away from the acute toxic dose- $\mathrm{LD}_{50}-(\sim 100 \mathrm{mg} / \mathrm{kg}$.$) and the chronic toxicosis dose (>2,000 \mathrm{ppm})$ that have been recently reported by Merck Manuals [21]. However, more studies are needed to determine the adequate zinc dosage alone or with other elements that fully protect against or even cure alcoholic hepatotoxicity with consideration of electron microscopic survey, immunohistochemical (as TUNEL) techniques and hepatic functions enzymes with biochemical markers.

In conclusion, the data of the present study support the role of ethanol-induced oxidative stress in explaining hepatotoxicity mechanisms that could be measured by histopathological and the parallel histochemical parameters as well as the role of zinc as an essential element and antioxidant to protect, ameliorate, modulate and even reverse these toxic effects. A dose of $10 \mathrm{~g} / \mathrm{kg} /$ day oral ethanol which almost equals $\mathrm{LD}_{50}$ is fair enough to produce acute alcoholic hepatotoxicity among rats and being equivalent to 4 times of repetitive binge-drinking ( $1.22 \mathrm{~g} / \mathrm{kg} /$ occasion) during 12 hours among humans. Furthermore, apoptosis whether being a product or a guard against toxicity, it is a good detector for the degree of toxicity as well as recovery. Amazingly, the liver is a unique and comprehensive biomarker to study the degree of ethanol toxicity as well as the protective and/or recovery measures. Zinc is qualified to be the first essential and the modest trace element in the map of prophylaxis and management of liver diseases. Finally, the classical histological, histochemical and morphometric techniques are fair enough to explore the big picture of these effects.

\section{References}

1. Sherlock S (1983) Current problems in alcoholic liver disease. Alcohol and Alcoholism 18: 99-118

2. Fifth Special Report to the U.S. Congress on Alcohol and Health from the Secretary of Health, Education and Welfare (1983). U.S. Department of Health and Human Services.

3. Rehm J, Mathers C, Popova S, Thavorncharoensap M, Teerawattananon $Y$ (2009) Global burden of disease and injury and economic cost attributable to alcohol use and alcohol-use disorders. The Lancet 373: 2223-2233.

4. http://www.etymonline.com

5. Dictionary.reference.com and www.medicinenet.com (2012). CWilliam Collins Sons \& Co. Ltd. CHarpers Collins Publishers.

6. www.medicalnewstoday.com/articles/157163.php

7. Stahre M, Roeber J, Kanny D, Brewer RD, Zhang X (2014) Contribution of excessive alcohol consumption to deaths and years of potential life lost in the United States. Prev Chronic Dis 11: 109

8. Van Thiel DH, Lester R, Sherins RJ (1974) Hypogonadism in alcoholic liver disease: evidence for double defects. Gastroenterology 67: 1188-1199.

9. Zhou Z, Sun X, Kang J (2002) Metallothionein protection against alcoholic liver injury through inhibition of oxidative stress. Exp Biol Med 227: 214-222.

10. Tietz NW (1986) Text book of clinical chemistry.(1stedn.) W. B. Saunders Company, Philadelphia, USA.

11. Powell SR (2000) The antioxidant properties of zinc. J Nutr 130: 1447-1454.

12. Marchesini G, Fabbri A, Zolis M (1996) Zinc supplementation and amino acidnitrogen metabolism in patients with advanced cirrhosis. Hepatology 23: 10841087.

13. Salonen RM, Nyss K, Porkkala-Sarataha E, Voutilaimen C, Rissaneen TH, et al. (2003) Six-year effect of combined vitamin C and E supplementation on atherosclerotic progression. Circulation107: 947-953.

14. Parizek J (1957) The destructive effect of cadmium ion on testicular tissue and its prevention by zinc. J Endocrinology 15: 56-63.

15. Perry DK, Smyth MJ, Stennicke HR, Salvesen GS, Duriez P, et al. (1997) Zinc is a potent inhibitor of the apoptotic protease caspase-3. A novel target for zinc in the inhibition of apoptosis. J Biol Chem 272: 18530-18533.

16. Truong-Tran AQ, Ho LH, Chai F, Zalewski PD (2000) Cellular zinc fluxes and regulation of apoptosis/gene-directed cell death. J Nutr 130: 1459-1466.

17. www.nlm.nih.gov/medlineplus

18. Carson EJ, Prutt SB (1996) Development and characterization of a binge drinking model in mice for evaluation of the immunological effects of ethanol. Alcohol Clin Exp Res 20: 132-138.

19. Zhou Z, Sun X, Kang J (2001) Ethanol-induced apoptosis in mouse liver; Fas and cytochrome c-mediated Caspase-3 activation. Am J Pathol 159: 329-338.

20. www.nlm.nih.gov/medline plus/ency/article/000944.htm

21. http://www.merckmanuals.com/vet/toxicology/zinc_toxicosis/overview_of_ zinc_toxicosis.html

22. Drury RAV, Wallington EA (1980) Carlton's Histological Techniques (5thedn.) Oxford University Press, New York, Toronto, USA.

23. Suvarna SK, Layton C, Bancroft JD (2012) Bancroft's Theory and Practice of Histological Techniques (7thedn.) Churchill Livingstone Elsevier, Philadelphia, PA,USA.

24. Gartner LP, Hiatt JL (2013) Digestive system glands: Liver lobules (6thedn.) Lippincott Williams \& Wilkins, USA.

25. Mescher AL (2013) Organs associated with the digestive tract: Liver. (13th edn), McGraw-Hill, USA

26. Fawcett DW, Jensh RP (2002) Liver and gallbladder (2ndedn.) Hodder Headline Group, London. 
Citation: Elshennawy ATM, Sayed SR, Saber EA, Rifaai RA (2015) Histopathological and Histochemical Assessment of the Protective Effects of Zinc on Ethanol-Induced Acute Hepatotoxicity in Adult Albino Rats. J Cytol Histol 6: 321. doi:10.4172/2157-7099.1000321

27. Prasad, AS (2014) Zinc in human health; Its discovery 50 years ago and the current impact. J Pharmacogenomics Pharmacoproteomics 5: 52.

28. Lambert JC, Zhou Z, Wang L, Song Z, McClain CJ, et al. (2003) Prevention of alterations in intestinal permeability is involved in zinc inhibition of acute ethanol-induced liver damage in mice. J Pharmacol Exp Ther 305: 880-886.

29. Thornberry N, Lazenbnik $Y$ (1998) Caspases: enemies within. Science 28: 1312-1316.

30. Sun XM, Mac Farlane M, Zhuang J, Wolf BB, Green DR, et al. (1999) Distinct caspase cascades are initiated in receptor-mediated and chemical-induced apoptosis. J Biol Chem 274: 5053-5060.

31. Neuman MG, Brenner DA, Rehermann B, Taieb J, Chollet-Martin S, et al (2001) Mechanisms of alcoholic liver disease; cytokines. Alcohol Clin Exp Res 25: $251-253$.

32. Brzóska MM, Moniuszko-Jakoniuk J, Piłat-Marcinkiewicz B, Sawicki B (2003) Liver and kidney function and histology in rats exposed to cadmium and ethanol. Alcohol Alcohol 38: 2-10.

33. Leist M, Gantner F, Kunstle G, Bohlinger I, Tiegs G, et al. (1996) The 55$\mathrm{kD}$ tumor necrosis factor receptor and CD95 independently signal murine hepatocyte apoptosis and subsequent liver failure. Mol Med 2: 109-124.

34. Nagata S (1999) Fas ligand-induced apoptosis. Annu Rev Genet 33: 29-55.

35. Bait ML, Lawson JA, Vonderfecht SL, Gujral JS, Jaeschke H (2000) Protection against Fas receptor-mediated apoptosis in hepatocytes and nonparenchymal cells by a caspase-8 inhibitor in vivo; evidence for a postmitochondrial processing of caspase-8. Toxicol Sci 58: 109-117.

36. Kawahara H, Matsuda Y, Takase S (1994) Is apoptosis involved in alcoholic hepatitis?. Alcohol Alcohol Suppl 29: 113-118.

37. Chomette G, Emerit J, Auriol M (1978) The hepatocyte in acute alcoholic hepatitis. Histoenzymological and ultrastructural analysis. Virchows Arch A Pathol Anat Histol 18: 31-48.

38. Christoffersen P, Braendstrup O, Juhl E, Poulsen H (1971) Lipogranulomas in human liver biopsies with fatty changes. Acta Pathol Microbiol Scanda A 79 : 150-158.

39. Garcia-Villafranca J, Guillen A, Castro J (2005) Desensitization of cyclic GMPmediated regulation of fatty acid metabolism in hepatocytes from ethanol-fed rats. Int J Biochem Cell Biol 37: 655-664.

40. Baker RC, Kramer RE (1999) Cytotoxicity of short chain alcohols. Annu Rev Pharmacol Toxicol 39: 127-150

41. Rouach H, Fataccioli V, Gentil M, French SW, Morimoto M, et al.(1997) Effect of chronic ethanol feeding on lipid peroxidation and protein oxidation on liver pathology. Hepatology 25: 351-355

42. Cederbraum Al (1999) Effect of alcohol on hepatic mitochondrial function and DNA. Gastroenterology 117: 265-269.

43. Baltaci AK, Ozyurek K, Mogulkoc R, Kurtoglu E, Ozkan Y, et al. (2003) Effects of zinc deficiency and supplementation on the glycogen contents of liver and plasma lactate and leptin levels of rats performing acute exercise. Biol Trace Elem Res 96: 227-236.

44. Uchida T, Kao H, Quispe-Sjogrens M, Peters RL (1983) Alcoholic foamy degeneration; a pattern of acute alcoholic injury of the liver. Gastroenterology 84: 683-692.

45. Remmer H, Kessler W, Einsele H, Hintze T, Diaz de Toranzo G, et al. (1989) Ethanol promotes oxygen-radical attack on proteins but not on lipids. Drug Metab Rev 20: 219-232.

46. Fucci L, Oliver C, Coon MJ, Stadtman ER (1983) Inactivation of key metabolic enzymes by mixed-function oxidation reactions; possible implication in protein turn-over and ageing. Proc Natl Acad Sci USA 80: 1521-1525.

47. Gebhardt R, Reicher J (1994) Changes in distribution and activity of glutathione synthetase in carbon tetrachloride-induced cirrhosis in the rat: potential role in hyperammonemia. Hepatology 20: 684-691.

48. Morimoto M, Hagbjork AL, Wan YJ, Fu PC, Clot P, et al. (1995) Modulation of experimental alcohol-induced liver disease by cytochrome P4502E1 inhibitors. Hepatology 21: 1610-1617

49. Wyllie AH (1997) Apoptosis; an overview. Br Med Bull 53: 451-465.

50. Lambert JC, Zhou Z, Kang YJ (2001) Zinc inhibition of caspase-3 activation does not protect HeLa cells from apoptotic cell death. Toxicol Appl Pharmaco 175: 89-93.

51. Smalinskienè A, Lesauskaitė V, Ryselis $S$, Abdrakhmanovas $O$, Kregždytė $R$ et al. (2006) Effects of six-week intoxication on cadmium and zinc distribution in internal organs and blood and on the mitotic activity of liver cells. Biologija 4: 76-79.

52. Smalinskienè A, Gaileviciūte R, Lesauskaitè V, Sadauskienè I, Abdrakhmanovas O, et al. (2005) Effects of cadmium and zinc ions on mitotic activity and protein synthesis in mouse liver. Medicina (Kaunas) 41: 506-511.

53. Jemai H, Messaoudi I, Chaouch A, Kerkeni A (2007) Protective effect of zinc supplementation on blood antioxidant defense system in rats exposed to cadmium. J Trace Elem Med Biol 21: 269-273.

54. Pathak A, Rathore AS, Bhutani V, Pathak R (2012) Role of zinc on antioxidative enzymes and lipid peroxidation in brain of diabetic rats. J Drug Metab Toxicol $3: 122$

55. El Heni J, Hammouda F, Messaoudi I, Kerkeni A, Sfar T (2013) Co-treatment with selenium and zinc: A probable therapy against cadmium toxicity. J Bioequiv Availab 5: 64.

56. Abassy MA, Marzouk MA, Mansour SA, Shaldam HA, Mossa AH (2014) Impact of oxidative stress and lipid peroxidation induced by Lambdacyholothrin on P450 in male rats: The ameliorating Effect of Zinc. J Environ Anal Toxicol 4 218

57. Arunakaran J (2012) Role of zinc on prostate cancer. J Bioequiv Availab 4: 57

58. Leist M, Single M, Castoldi AF, Kühnle S, Nicotera $P$ (1997) Intracellula adenosine triphosphate (ATP) concentration: a switch in the decision between apoptosis and necrosis. J Exp Med 185: 1481-1486.

59. Matsushita K, Kitagawa K, Matsuyama T, Ohtsuki T, Taguchi A, et al. (1996) Effect of systemic zinc administration on delayed neuronal death in the gerbil hippocampus. Brain Res 743: 362-365.

60. Waring P, Egan M, Braithwaite A, Mullbacher A, Sjaarda A (1990) Apoptosis induced in macrophages and $T$ blasts by the mycotoxin sporidesmin and protection by $\mathrm{Zn}^{2+}$ salts. Int J Immunopharmac 12: 445-457

61. Mahran AA, Husam Eldien HO, Abd El-Mawla AMA, Attia AM (2011) Protective effect of zinc $(\mathrm{Zn})$ on the histology and histochemistry of liver and kidney of albino rat treated with cadmium. J Cytol Histol 2:123.

62. Floersheim GL, Christ A, Koenig R, Racine C, Gudat F (1992) Radiationinduced lymphoid tumors and radiation lethality are inhibited by combined treatment with small doses of zinc aspartate and WR 2721. Int J Cancer 52 : 604-608.

63. Vallee B L, Falchuk KH (1993) The biochemical basis of zinc physiology. Physiology Rev 73: 79-118

64. Deuciac IV, D'Souza NB, Spitzer JJ (1995) Tumor necrosis factor- $\alpha$ cell-surface receptors of liver parenchymal and nonparenchymal cells during acute and chronic alcohol administration to rats. Alcohol Clin Exp Res 19: 332-338.

65. Caballería J, Giménez A, Andreu H, Deulofeu R, Parés A, et al. (1997) Zinc administration improves gastric alcohol dehydrogenase activity and first pass metabolism of ethanol in alcohol-fed rats. Alcohol Clin Exp Res 21: 1619-1622.

66. Dashti HM, Mathew TC, Jadaon MM, Ashkanani E (1997) Zinc and live cirrhosis: biochemical and histopathologic assessment. Nutrition 13: 206-212.

67. Pathology Biology and Diseases (2012) Alcohol hepatotoxicity; Alcohol liver damage. Information on Pathology, Biology, Animals, Plants, Microbes and Diseases. BiologyDisease.com @ 2012

68. Sato N, Lindros KO, Baraona E, Ikejima K, Mezey E, et al. (2001) Sex difference in alcohol-related organ injury. Alcohol Clin Exp Res 25: 40-45.

69. O'Connor P G (2011) Alcohol abuse and dependence (24thedn.) Elsevier Philadelphia,USA.

70. Kampov-Polevoi AB, Skal'nyi AV (1989) Reduction of acute ethanol toxicity by zinc sulphate. Bull Exp Biol Med 107: 346-348.

71. http://msds.chem.ox.ac.uk/ET/ethyl_alcohol.html

72. http://ccinfoweb.ccohs.ca/help/msds/msdstermse.htm

73. http://www.alcohol.org.nz/alcohol-you/your-body-alcohol/references\#.dpuf

74. Vonghia L, Leggio L, Ferrulli A, Bertini M, Gasbarrini G ,et al. (2008) Acute 
Citation: Elshennawy ATM, Sayed SR, Saber EA, Rifaai RA (2015) Histopathological and Histochemical Assessment of the Protective Effects of Zinc on Ethanol-Induced Acute Hepatotoxicity in Adult Albino Rats. J Cytol Histol 6: 321. doi:10.4172/2157-7099.1000321

Page 8 of 8

alcohol intoxication. Eur J Intern Med 19: 561-567.

75. Dares MS, Townsend SM, Wooles WR (1986) Protective effect of zinc against ethanol toxicity in mice. J Toxicol Environ Health 18: 41-48.

76. Al-Amoudi W (2015) Ameliorative Role and Antioxidant Effect of Propolis against Hepatotoxicity of Fenvalerate in Albino Rats. J Cytol Histol 6: 303.
77. Loganathan K, Velmurugan B, Hongray Howrelia J, Selvanayagam M, Patnaik BB (2006) Zinc induced histological changes in brain and liver of Labeo rohita (Ham.). J Environ Biol 27: 107-110.

78. Turgut G, Abban G, Turgut S, Take G (2003) Effect of overdose zinc on mouse testis and its relation with sperm count and motility. Biol Trace Elem Res 96: 271-274. 